\title{
CALIBRAÇÃo VISANDO À FERTILIZAÇÃo COM FÓSFORO PARA AS PRINCIPAIS CULTURAS DE GRÃOS SOB SISTEMA PLANTIO DIRETO NO PARAGUAI ${ }^{(1)}$
}

\author{
Martin Maria Cubilla ${ }^{(2)}$, Telmo Jorge Carneiro Amado ${ }^{(3)}$, Ademir \\ Wendling $^{(4)}$, Flávio Luíz Foletto Eltz ${ }^{(5)}$ \& João Mielniczuk ${ }^{(6)}$
}

\begin{abstract}
RESUMO
Atualmente, em torno de $60 \%$ da área de cultivo de grãos do Paraguai está sob sistema plantio direto (SPD). Com a expansão desse sistema conservacionista no país, surgiram questionamentos quanto à adequação das recomendações de fertilizantes, especialmente de $P$, pois elas foram elaboradas com base em experimentos realizados sob sistema convencional de preparo de solo e com defasagem de tempo de 15 anos. O principal objetivo deste trabalho foi gerar recomendações atualizadas de adubação fosfatada para as culturas de trigo, milho e soja sob SPD. Para isso, no período de 2003 a 2005 foram realizados experimentos de calibração em rede, abrangendo sete diferentes locais na região oriental do Paraguai. Esses experimentos foram realizados sob SPD em solos com diferentes históricos de sistemas de manejo, texturas e níveis de fertilidade, em regiões representativas da produção de grãos. O delineamento experimental foi de blocos ao acaso com parcelas subdivididas, com três repetições. As parcelas principais, quando da implantação, foram adubadas com cinco doses de $P(0,50,100,200$ e $400 \mathrm{~kg} \mathrm{ha}^{-1} \mathrm{de}_{2} \mathrm{P}_{5}$ ), visando à criação de níveis de fertilidade. Após implantação do experimento, no segundo cultivo foram criadas as subparcelas, nas quais foram aplicadas quatro doses de $P\left(0,40,80\right.$ e $120 \mathrm{~kg} \mathrm{ha}^{-1}$ de $\left._{2} \mathrm{O}_{5}\right)$. A fonte de $P$ utilizada foi o superfosfato triplo, sendo todas as aplicações realizadas a lanço. $O$ potássio, nitrogênio e calagem foram aplicados uniformemente, em quantidades não limitantes, em todas as parcelas. A amostragem de solo foi feita antes da implantação do experimento e após cada colheita com 10 subamostras, para compor
\end{abstract}

\footnotetext{
(1) Parte da Tese de Mestrado do primeiro autor. Trabalho financiado pela Câmara Paraguaia de Exportadores de Cereais e Oleaginosas - CAPECO. Recebido para publicação em novembro de 2006 e aprovado em julho de 2007.

${ }^{(2)}$ Engenheiro-Agrônomo, Mestre em Ciência do Solo. Sucre 2002 Assunção Paraguai. E-mail: cubilla@ksu.edu

${ }^{(3)}$ Professor do Departamento de Solos, Universidade Federal de Santa Maria - UFSM. CEP 97110-970 Santa Maria (RS). Bolsista do CNPq. E-mail: tamado@smail.ufsm.br

(4) Mestre em Ciência do Solo, BASE Precisão na Agricultura. Santa Maria (RS). Av. Roraima 03, Caixa Postal 5053, CEP 97110970 Santa Maria (RS). E-mail: ademir@baseap.ufsm.br

${ }^{(5)}$ Professor do Departamento de Solos, UFSM. Bolsista do CNPq. E-mail: feltz@ccr.ufsm.br

${ }^{(6)}$ Professor Colaborador do Departamento de Solos, Universidade Federal do Rio Grande do Sul - UFRGS. Av. Bento Gonçalves 7712, CEP 91540-000 Porto Alegre (RS). Bolsista do CNPq. E-mail: mieln@vortex.ufrgs.br
} 
uma amostra por subparcela, sempre na profundidade de 0-10 cm. Neste trabalho, a construção da disponibilidade de $P$ sob SPD foi mais influenciada pelo teor inicial do nutriente e histórico de adubação do que pela textura do solo. Em solos com baixo teor inicial de $P$ e com histórico de adubação limitada, foi necessário aplicar em média 35,3 kg ha-1 de $\mathrm{P}_{2} \mathrm{O}_{5}$ para elevar $1 \mathrm{mg} \mathrm{dm}^{-3}$ de $\mathrm{P}$ disponível no solo. Por outro lado, para solos com teor médio a alto e com histórico de adubação adequada, foi preciso aplicar $18,6 \mathrm{~kg} \mathrm{ha}^{-1} \mathrm{de}_{2} \mathrm{O}_{5}$. $O$ teor crítico de $P$ encontrado neste trabalho foi ligeiramente superior ao anteriormente proposto. Assim, o teor crítico estimado, com base em Mehlich-1, para solos com 410-600 $\mathrm{g} \mathrm{kg}^{-1}$ de argila (classe 1) foi de $12 \mathrm{mg} \mathrm{dm}^{-3}$, e para solos com 210 a $400 \mathrm{~g} \mathrm{~kg}^{-1}$ de argila (classe 2 ) foi de $15 \mathrm{mg} \mathrm{dm}^{-3}$. Com base nessas informações, foi apresentada uma recomendação preliminar de fertilização fosfatada adaptada ao SPD no Paraguai.

Termos de indexação: fertilidade do solo, conservação do solo, teor crítico, curva de resposta, soja, milho, trigo.

\title{
SUMMARY: CALIBRATIONOF PHOSPHORUS FERTILIZATION RATESFOR MAIN GRAIN CROPS UNDER NO-TILL IN PARAGUAY
}

\begin{abstract}
Presently, approximately $60 \%$ of the grain crop area in Paraguay is under no-till (NT). With the expansion of NT in the country, some doubts were raised with respect to the obsoleteness of fertilizer recommendations, especially regarding phosphorus $(P)$. The last $P$ fertilizer recommendation had been established for conventional soil tillage system 15 years earlier. The main objective of this work was to update phosphate fertilizer recommendations for wheat, corn and soybean under NT. Seven different locations in eastern Paraguay were evaluated in a experimental calibration net. The experiments were carried out from 2003 to 2005 in a range of soils with different preceding soil management systems, textures and initial soil fertility levels, in representative regions of the grain production area under NT. The experimental design was randomized blocks with split plots and three repetitions. In the first season the main plots received five $P$ rates $(0,50$, 100,200 , and $400 \mathrm{~kg} \mathrm{ha}^{-1}$ of $\mathrm{P}_{2} \mathrm{O}_{5}$ ) to establish different soil fertility levels. In the second season, four $P$ rates $\left(0,40,80\right.$ and $120 \mathrm{~kg} \mathrm{ha}^{-1}$ of $\left.\mathrm{P}_{2} \mathrm{O}_{5}\right)$ were applied on the split plots to obtain the crop response curve. The phosphorus source was triple super phosphate, broadcast on soil surface. The building up of $P$ in NT was more influenced by the initial P level than by soil texture. In soils with low initial $P$ level it was necessary to apply $36.5 \mathrm{~kg} \mathrm{ha}^{-1} \mathrm{P}_{2} \mathrm{O}_{5}$ to increase available soil $P$ by $1 \mathrm{mg} \mathrm{dm}^{-3}$, while in soils with medium to high initial $P$, $18.6 \mathrm{~kg} \mathrm{ha}^{-1}$ was needed. The sufficient P level obtained in this study was slightly higher than predicted by the previous recommendation. Thus, the sufficiency P level (Mehlich-1) for soils ranging from 410 to $600 \mathrm{~g} \mathrm{~kg}^{-1}$ clay is $12 \mathrm{mg} \mathrm{dm}^{-3}$ and for soils ranging from 210 to $400 \mathrm{~g} \mathrm{~kg}^{-1}$ clay is $15 \mathrm{mg} \mathrm{dm} \mathrm{dm}^{-3}$. This paper proposes a preliminary $P$ fertilization recommendation adapted to no-till in Paraguay.
\end{abstract}

Index terms: soil fertility, soil conservation, sufficient P level, phosphorus response curve, soybean, maize, wheat.

\section{INTRODUÇÃO}

A superfície total do Paraguai é de $406.752 \mathrm{~km}^{2}$, dos quais $159.827 \mathrm{~km}^{2}(39,3 \%)$ correspondem à Região Oriental do país e os restantes $60,7 \%$ pertencem à Região Ocidental ou Chaco Boreal. A Região Oriental está mais desenvolvida do que a Região Ocidental devido a fatores climáticos e geográficos, concentrando $98,6 \%$ da população do país. Em 2004, aproximadamente $60 \%$ da área sob cultivo agrícola no Paraguai foi utilizada sob sistema plantio direto (SPD) (Derpsch $\&$ Benites, 2004), com destaque para o sudeste, oeste e nordeste da Região Oriental.
Com o avanço da adoção do SPD no Paraguai, surgiram dúvidas quanto à adequação das recomendações de fertilizantes, especialmente as de $\mathrm{P}$, pois elas foram elaboradas com base em experimentos realizados sob sistema convencional de preparo de solo (aração + gradagens) (Fatecha, 1999), portanto, em condições muito distintas daquelas do atual sistema conservacionista, que se caracteriza pelo mínimo revolvimento e manutenção dos resíduos culturais na superfície do solo.

Quando o SPD é adotado por mais de 10 anos, as principais propriedades determinantes da produtividade do solo podem ser alteradas. Dentre as 
mudancas verificadas na fertilidade do solo sob SPD consolidado, destacam-se: (a) redução da adsorção de $\mathrm{P}$ na superfície de óxidos devido ao menor revolvimento, fato que anteriormente ocorria com intensidade quando os solos tropicais eram submetidos a freqüente mobilização (Eltz et al., 1989; Sá, 1993; Martins \& Gonçalves, 1997); (b) elevada concentração superficial de nutrientes, notadamente o $\mathrm{P}$, especialmente na camada de 0 a $0,05 \mathrm{~m}$, raramente ultrapassando a profundidade de $0,10 \mathrm{~m}$ (Muzilli, 1983; Sidiras \& Pavan, 1986; Eltz et al., 1989; Sá, 1993; Schlindwein \& Anghinoni, 2000); (c) incremento do teor de matéria orgânica nessa mesma camada superficial (Sidiras \& Pavan, 1986; Bayer et al., 2000; Schlindwein \& Anghinoni, 2000; Amado et al., 2002), que obstrui parcialmente os sítios de adsorção de $\mathrm{Pe}$ aumenta o armazenamento de água no solo, permitindo melhor aproveitamento pelas plantas dos fertilizantes aplicados; $\mathrm{e}(\mathrm{d})$ redução nas perdas de solo e de nutrientes por erosão, devido à proteção proporcionada pelos resíduos culturais mantidos na superfície do solo (Eltz et al., 1989). Essas alterações na fertilidade do solo, induzidas pelo SPD, podem influenciar a disponibilidade de nutrientes às plantas e, conseqüentemente, as recomendações de adubação.

Nas últimas duas décadas, com a adoção do SPD, foram introduzidas significativas mudanças na produção de grãos no Paraguai, com reflexos na fertilidade do solo, destacando-se a amostragem do solo, que passou a ser feita na camada de maior concentração de nutrientes $(0-0,10 \mathrm{~m})$, e o gradativo incremento de produtividade média das principais culturas, devido ao melhoramento genético e ao aprimoramento das práticas de manejo. Exemplificando, na década de 1980 a produtividade de soja era de 1,67 t ha-1 ${ }^{-1}$ com produção total de 1,6 Mt; já na década de 1990 a produtividade subiu para $2,64 \mathrm{t} \mathrm{ha}^{-1}$, com produção total de 3,2 t (FAOSTAT, 2005).

No Paraguai ainda são escassas as informações a respeito dos ajustes necessários na recomendação de fertilizantes, em geral, e de P, especificamente, para acompanhar os recentes avanços introduzidos no sistema produtivo, com destaque para a adoção do SPD. Esse fato é o objeto central deste trabalho. Para isso, foram realizados experimentos de calibração em rede, em diferentes localidades, visando à obtenção de recomendação preliminar de adubação fosfatada para as culturas de trigo, milho e soja sob SPD.

\section{MATERIAL E MÉTODOS}

A Região Oriental do Paraguai, onde foram realizados os experimentos, localiza-se entre as coordenadas geográficas $22^{\circ} 05^{\prime}$ e $27^{\circ} 30$ ' latitude sul e entre $54^{\circ} 15^{\prime}$ e $58^{\circ} 38^{\prime}$ longitude oeste de Greenwich. O clima predominante na Região Oriental é classificado, segundo Köppen, como Cfa subtropical úmido, mesotérmico, com verões quentes e invernos com geadas ocasionais. As chuvas ocorrem com maior frequência na primavera/verão, sem estação de seca definida. A precipitação média anual oscila entre $1.300 \mathrm{~mm}$ a oeste e $1.900 \mathrm{~mm}$ a leste dessa região, e a temperatura média mensal do ar varia de 17 a $27^{\circ} \mathrm{C}$.

As áreas experimentais foram selecionadas com base na representatividade agrícola, classe textural do solo, teor inicial de $\mathrm{P}$, histórico de adubação e de sistemas de manejo e no tempo de adoção do SPD. Assim, sete experimentos foram implantados em diferentes regiões do país, sendo dois no Departamento de Misiones (M1 e M2), dois no Departamento de Itapúa (I1 e I2), dois no Departamento do Alto Paraná (AP1 e AP2) e um no Departamento de Amambay (PJC1) (Figura 1).

No quadro 1 são apresentadas as principais características químicas do solo de cada área experimental, antes da instalação do experimento. Neste quadro, a classificação dos solos utilizada foi a Classificação Americana (Soil Taxonomy), que é a adotada no Paraguai (López et al., 1995), e a correspondente brasileira. Anteriormente à implantação do experimento, as áreas eram utilizadas com diferentes sistemas de manejo (produção de grãos e pastagem) e com diferentes tempos de adoção de SPD (Quadro 1). Os sistemas de cultura utilizados nos experimentos foram trigo (Triticum aestivum L.) / soja (Glycine max (L.) Merril) / trigo e trigo / milho (Zea mays L.) / trigo, que são os predominantes nas regiões agrícolas investigadas.

O delineamento experimental utilizado foi o de blocos ao acaso, com parcelas subdivididas e três repetições. As parcelas principais, visando à criação de níveis de fertilidade, foram adubadas, nos experimentos M1 e I1, no mês de maio de 2003, com cinco doses de $\mathrm{P}\left(0,50,100,200\right.$ e $\left.400 \mathrm{~kg} \mathrm{ha}^{-1} \mathrm{de}_{2} \mathrm{O}_{5}\right)$, sendo posteriormente cultivado o trigo. Em novembro de 2003, essas áreas foram divididas em duas partes iguais, nas quais foram cultivadas a soja e o milho e criadas as subparcelas, por meio da aplicação de quatro doses de $\mathrm{P}\left(0,40,80\right.$ e $120 \mathrm{~kg} \mathrm{ha}^{-1}$ de $\left._{2} \mathrm{O}_{5}\right)$, visando à obtenção de curva de resposta nos diferentes níveis de fertilidade anteriormente criados. Para os demais locais (M2, I2, AP1, AP2 e PJC1), o experimento foi iniciado seis meses após a implantação de M1 e I1, nas culturas de verão, com a adubação visando à criação de níveis de fertilidade. Em maio de 2004, nesses locais, foram criadas as subparcelas na cultura do trigo. Assim, em M1 e I1 foram cultivados dois anos de trigo e um ano de soja e milho, enquanto nos demais, um ano para cada cultura.

A adubação de criação de níveis de fertilidade foi feita uma vez por local, quando da instalação do experimento. Já as adubações visando à obtenção da curva de resposta (subparcelas) foram feitas antes de cada cultura, respeitando as quantidades estabelecidas. As dimensões das subparcelas experimentais foram de $5 \times 8 \mathrm{~m}$, e as das parcelas principais, de $8 \times 20 \mathrm{~m}$. 


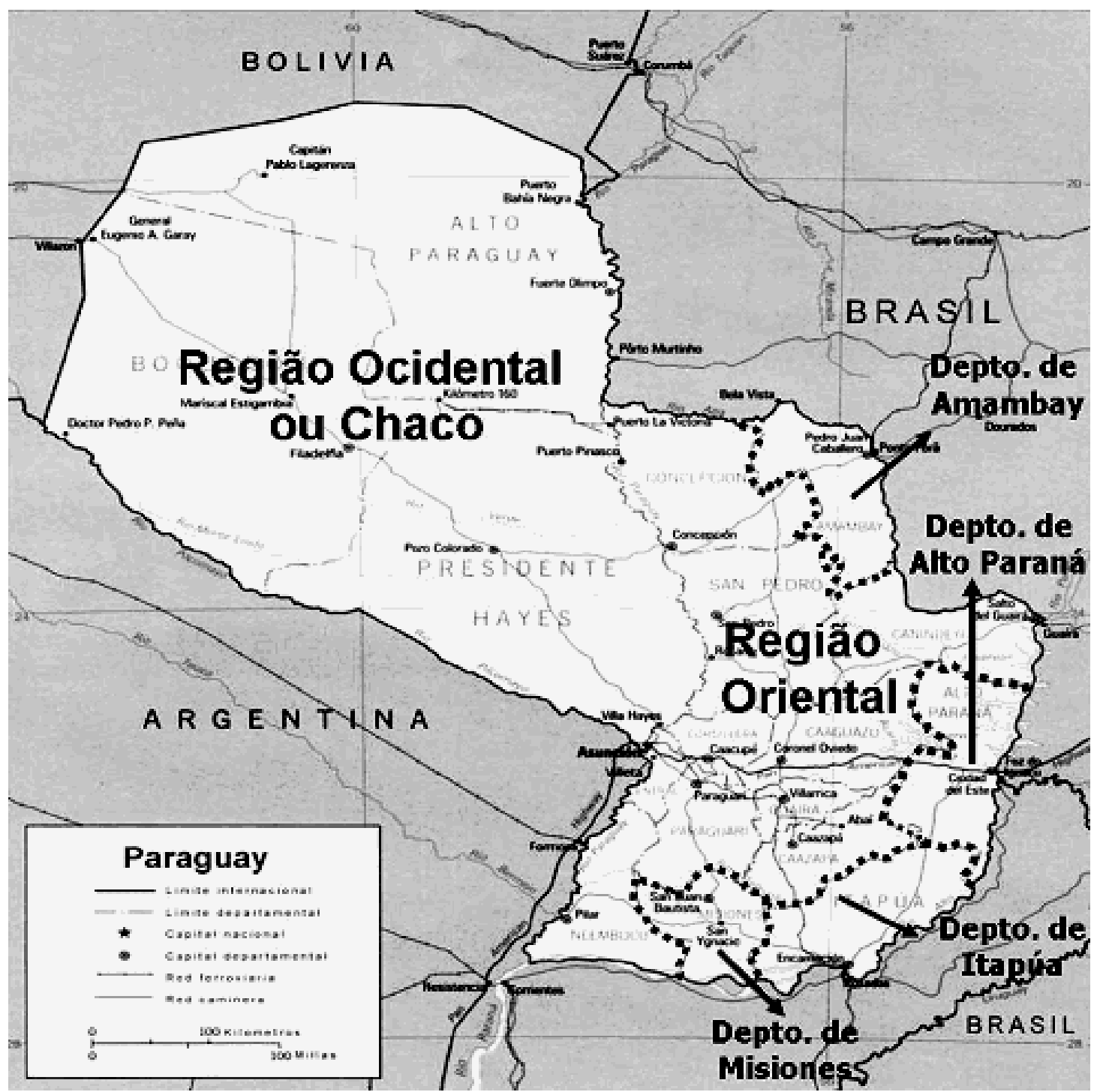

Figura 1. Mapa do Paraguai com os Departamentos onde foram realizados os experimentos de calibração (Departamentos de Misiones, Itapúa, Alto Paraná e Amambay).

Todos os experimentos foram realizados sob sistema plantio direto.

As semeaduras foram efetuadas nas épocas preconizadas pelas recomendações técnicas regionais, objetivando atingir as máximas produções das culturas. O trigo foi sempre semeado no mês de maio, enquanto o milho e a soja foram semeados em novembro. As cultivares utilizadas foram as mais cultivadas e produtivas, e nas regiões de condução dos experimentos não foi utilizada irrigação suplementar (Quadro 2).

As adubações de $\mathrm{K}$ e $\mathrm{N}$ foram mantidas constantes e satisfatórias para atender à demanda das culturas, utilizando-se para o primeiro nutriente a dose de $50 \mathrm{~kg} \mathrm{ha}^{-1}$ de $\mathrm{K}_{2} \mathrm{O}$ nas culturas do trigo e da soja e $75 \mathrm{~kg} \mathrm{ha}^{-1}$ de $\mathrm{K}_{2} \mathrm{O}$ no milho; e, para o segundo, $60 \mathrm{~kg} \mathrm{ha}^{-1}$ de $\mathrm{N}$ no trigo (20 $\mathrm{kg} \mathrm{ha}^{-1}$ na semeadura e $40 \mathrm{~kg} \mathrm{ha}^{-1}$ em cobertura) e $180 \mathrm{~kg} \mathrm{ha}^{-1}$ de $\mathrm{N}$ no milho
(30 kg ha-1 na semeadura e $150 \mathrm{~kg} \mathrm{ha}^{-1}$ em cobertura), aplicados no período dos 30 aos 40 dias depois da semeadura. As fontes dos nutrientes utilizadas neste trabalho foram: o cloreto de potássio, $58 \%$ de $\mathrm{K}_{2} \mathrm{O}$; a uréia, $45 \%$ de $\mathrm{N}$; e o superfosfato triplo, $41 \%$ de $\mathrm{P}_{2} \mathrm{O}_{5}$. As aplicações dos nutrientes foram realizadas manualmente a lanço; para isso, as subparcelas foram delimitadas com cordas nos quatro limites, definindo exatamente a área de aplicação. No entanto, na cultura do milho o $\mathrm{N}$ foi aplicado em linha, manualmente, visando aumentar a eficiência de utilização do nutriente.

No cultivo de trigo, para medir a produção de 2003 coletaram-se três amostras ao acaso de $0,25 \mathrm{~m}^{2}$, totalizando $0,75 \mathrm{~m}^{2}$ avaliado por parcela. Já nas culturas do milho e da soja coletaram-se 6 m lineares (duas linhas de $3 \mathrm{~m}$ ), localizadas no centro das 
Quadro 1. Classificação de solo, localização geográfica dos experimentos, características químicas e teor de argila na camada 0-10 cm, e histórico de manejo anterior à instalação dos experimentos. Paraguai, 2005

\begin{tabular}{|c|c|c|c|c|c|c|c|c|c|}
\hline Local & Solo & Latitude & Longitude & $\begin{array}{c}\mathbf{p H} \\
\mathrm{H}_{2} \mathrm{O}\end{array}$ & Argila & MO & $\mathbf{P}$ & $\mathbf{K}^{+}$ & $\begin{array}{c}\text { Histórico de manejo } \\
\text { anterior a } \\
\text { implantação do } \\
\text { experimento }\end{array}$ \\
\hline & & & & & \multicolumn{2}{|c|}{$-\mathrm{g} \mathrm{kg}^{-1}$} & $\mathrm{mg} \mathrm{dm}^{-3}$ & $\mathrm{cmol}_{\mathrm{c}} \mathrm{dm}^{-3}$ & \\
\hline M1 & $\begin{array}{l}\text { Ultisol }^{(1)} \\
\text { Argissolo }\end{array}$ & $26^{\circ} 59^{\prime} 55^{\prime \prime}$ & $56^{\circ} 45^{\prime} 02^{\prime \prime}$ & 5,2 & 250 & 25 & 11,9 & 0,12 & $\begin{array}{l}\text { PD estabelecido } \\
\text { produção de grãos com } \\
\text { adubação adequada }^{(3)}\end{array}$ \\
\hline M2 & $\begin{array}{l}\text { Ultisol }^{(1)} \\
\text { Argissolo }\end{array}$ & $26^{\circ} 59^{\prime} 05^{\prime \prime}$ & $56^{\circ} 44^{\prime} 11^{\prime \prime}$ & 5,1 & 250 & 27 & 4,3 & 0,32 & $\begin{array}{l}\text { Pastagem de } \\
\text { braquiária com } \\
\text { adubação limitada }\end{array}$ \\
\hline $\mathrm{I} 1$ & $\begin{array}{l}\text { Oxisol }^{(1)} \\
\text { Latossolo }^{2}\end{array}$ & $26^{\circ} 56^{\prime} 07^{\prime \prime}$ & $55^{\circ} 38^{\prime} 04^{\prime \prime}$ & 5,6 & 475 & 30 & 12,7 & 0,53 & $\begin{array}{l}\text { PD estabelecido } \\
\text { produção de grãos com } \\
\text { adubação adequada }\end{array}$ \\
\hline $\mathrm{I} 2$ & $\begin{array}{l}\text { Ultisol }^{(1)} \\
\text { Argissolo }\end{array}$ & $27^{\circ} 08^{\prime} 54^{\prime \prime}$ & $56^{\circ} 03^{\prime} 46^{\prime \prime}$ & 6,2 & 355 & 25 & 3,5 & 0,50 & $\begin{array}{l}\text { PD em fase inicial } \\
\text { implantado em área } \\
\text { com indícios de } \\
\text { degradação produção } \\
\text { de grãos com } \\
\text { adubação limitada }\end{array}$ \\
\hline $\mathrm{AP} 1$ & $\begin{array}{l}\text { Oxisol }^{(1)} \\
\text { Latossolo }^{2}\end{array}$ & $25^{\circ} 27^{\prime} 23^{\prime \prime}$ & $55^{\circ} 02^{\prime} 49^{\prime \prime}$ & 5,3 & 395 & 29 & 7,6 & 0,52 & $\begin{array}{l}\text { PD estabelecido } \\
\text { produção de grãos com } \\
\text { adubação adequada }\end{array}$ \\
\hline AP2 & $\begin{array}{l}\text { Alfisol }^{(1)} \\
\text { Latossolo }^{2}\end{array}$ & $25^{\circ} 58^{\prime} 07^{\prime \prime}$ & $55^{\circ} 12^{\prime} 49^{\prime \prime}$ & 6,5 & 470 & 42 & 7,9 & 0,92 & $\begin{array}{l}\text { PD estabelecido } \\
\text { produção de grãos com } \\
\text { adubação adequada }\end{array}$ \\
\hline PJC1 & $\begin{array}{l}\text { Alfisol }^{(1)} \\
\text { Latossolo }^{2}\end{array}$ & $22^{\circ} 39^{\prime} 18^{\prime \prime}$ & $55^{\circ} 53^{\prime} 36^{\prime \prime}$ & 6,7 & 560 & 44 & 5,2 & 0,65 & $\begin{array}{l}\text { PD em fase inicial } \\
\text { produção de grãos com } \\
\text { adubação limitada }\end{array}$ \\
\hline
\end{tabular}

M1: Misiones 1, M2: Misiones 2, I1: Itapúa 1, I2: Itapúa 2, AP1: Alto Paraná1, AP2: Alto Paraná2, PJC1: Pedro Juan Cabaleiro, T: trigo, B: braquiária, M: milho, S: soja. (1) Classificação Americana de Solos, Soil taxonomy, utilizada no levantamento de solos do Paraguai (López et al., 1995). (2) PD estabelecido: plantio direto com mais de 10 anos sem preparo. PD em fase inicial: plantio direto com menos de 10 anos. (3) Adubação adequada: reposição integral dos nutrientes exportados via colheita. Adubação limitada: reposição parcial dos nutrientes exportados.

Quadro 2. Cultivares utilizadas nos anos e locais de condução do experimento. Paraguai, 2005

\begin{tabular}{|c|c|c|c|c|}
\hline Experimento & Trigo/2003 & Milho/2003/04 & Soja/2003/04 & Trigo/2004 \\
\hline $\mathrm{M} 1^{(1)}$ & Itapúa 40 & AS 3466/Agroeste & RR 5409 & Itapúa 40 \\
\hline M2 & - & As 3466/Agroeste & RR 5409 & Itapúa 40 \\
\hline $\mathrm{I} 1$ & Itapúa 50 & Crioula $^{(2)}$ & Guapa 5.5 & Itapúa 40 \\
\hline $\mathrm{I} 2$ & - & 9010 Monsanto & Nidera 8000 & Itapúa 40 \\
\hline $\mathrm{AP} 1$ & - & - & Codetec 215 & Itapúa 40 \\
\hline $\mathrm{AP} 2$ & - & 9010 Monsanto & Nidera 4910 & Itapúa 45 \\
\hline PJC1 & - & BR 106 & Codetec 205 & Itapúa 45 \\
\hline
\end{tabular}

(1) M1: Misiones 1; M2: Misiones 2; I1: Itapúa 1; I2: Itapúa 2; AP1: Alto Paraná 1; AP2: Alto Paraná 2; PJC1: Pedro Juan Caballero 1. ${ }^{(2)}$ Semente produzida na propriedade. 
subparcelas. Para o trigo de 2004 foi coletada uma área central de $3,2 \mathrm{~m}^{2}$ por subparcela, com uma colhedora de precisão austríaca da marca Wintersteiger. As colheitas de trigo foram efetuadas no mês de outubro nos respectivos anos, enquanto as do milho e da soja foram efetuadas em março e abril de 2004, respectivamente. Todas as produtividades foram corrigidas para $13 \%$ de umidade.

As coletas de solo foram feitas após cada colheita das culturas, sendo efetuadas 10 subamostras por subparcela, compondo uma amostra composta. Todas as amostras foram coletadas na camada de $0-10 \mathrm{~cm}$ de profundidade. As análises foram processadas no laboratório de solos da Universidade Federal de Santa Maria, seguindo método descrito por Tedesco et al. (1995). O método de laboratório para determinação do P foi o de Mehlich-1, utilizando o colorímetro.

O rendimento relativo das culturas foi obtido pela equação:

$$
\mathrm{RR}=\frac{\text { Rendimento da cultura na testemunha }(\mathrm{sem} \mathrm{P})}{\text { Rendimento máximo da cultura }} \times 100
$$

em que $\mathrm{RR}=$ rendimento relativo em \%.

$O$ rendimento da cultura no tratamento sem $P$ foi estimado pela função de produção ajustada, ou seja, o intercepto "a" da equação de regressão entre as doses de $\mathrm{P}$ e o rendimento de grãos. Para o valor de rendimento máximo da cultura foi utilizado o valor estimado pela equação de regressão. No caso do uso de equações lineares com respostas positivas à aplicação de $\mathrm{P}$, o valor de rendimento máximo foi o correspondente à maior dose utilizada; no caso de resposta negativa, o rendimento máximo foi o correspondente à dose zero de $\mathrm{P}$ (intercepto da equação de regressão). Quando foram empregadas funções de regressão de segundo grau, utilizou-se a técnica de derivação das funções para obtenção do valor de rendimento máximo.

A curva de calibração foi obtida pela relação entre os teores de $\mathrm{P}$ no solo determinados pelo método Mehlich-1 e os valores de rendimento relativo calculado pela equação (1). A equação selecionada (2) para o ajuste dos dados da calibração foi a forma exponencial da equação de Mitscherlich, sendo esta equação forçada a alcançar o rendimento relativo de $100 \%$.

$$
\mathrm{y}=\mathrm{A}\left(1-10^{-\mathrm{cx}}\right)
$$

em que $\mathrm{y}=$ rendimento relativo $(\mathrm{RR}) ; \mathrm{A}=$ rendimento máximo; $\mathrm{c}=$ coeficiente de eficiência do $\mathrm{P}$; e $\mathrm{x}=$ quantidade de $\mathrm{P}$ em $\mathrm{kg} \mathrm{ha}^{-1}$.

O teor crítico foi definido como a concentração do nutriente no solo necessária para alcançar $90 \%$ do rendimento máximo da cultura, seguindo método utilizado nos programas de adubação do Rio Grande do Sul (RS) e Santa Catarina (SC) (Mielniczuk et al., 1969a,b; UFRGS, 1973, 1976; Manual..., 1981; Siqueira et al., 1987; CQFSRS/SC, 2004).
O teor crítico foi utilizado para definir as cinco classes de fertilidade do solo. O limite superior da classe média foi igual ao teor crítico, que, dividido por três, estabeleceu o limite entre as classes baixa e muito baixa. Acima do teor crítico também foram estabelecidas duas classes de fertilidade, sendo o teor crítico multiplicado por dois para definição do limite entre as classes alta e muito alta, conforme proposto pela CQFSRS/SC (2004).

Para estimativa do poder-tampão de $\mathrm{P}$ do solo, determinaram-se as equações de incremento do $\mathrm{P}$ disponível no solo às aplicações de doses desse nutriente. Nestas, o coeficiente de regressão linear das equações lineares correspondeu ao incremento de $\mathrm{P} \mathrm{mg} \mathrm{dm}{ }^{-3}$ por kg ha-1 de $\mathrm{P}_{2} \mathrm{O}_{5}$ aplicado. Por meio de regra de três simples, foi determinada a quantidade de $\mathrm{P}_{2} \mathrm{O}_{5}$ necessária para elevar uma unidade de $\mathrm{mg} \mathrm{dm}^{-3}$ de P disponível no solo. Essas informações, juntamente com dados de literatura, foram a base usada para elaboração da recomendação preliminar de fertilização de P para as culturas de grãos sob SPD no Paraguai, a qual foi ajustada em reunião da RENALAS (RENALAS, 2005).

\section{RESULTADOS E DISCUSSÃO}

\section{Determinação do teor crítico de fósforo}

Os rendimentos das culturas de trigo, soja e milho nos experimentos foram compatíveis com os rendimentos médios obtidos em lavouras comerciais no Paraguai. Na maioria dos experimentos houve resposta à aplicação de $\mathrm{P}$, exceto em situações em que os teores iniciais foram muito altos ou quando ocorreu déficit hídrico regionalizado. Detalhes desses resultados foram apresentados por Cubilla (2005).

O teor de argila do solo, devido à sua influência na disponibilidade de $\mathrm{P}$ às plantas, tem sido um dos principais fatores considerados nas recomendações de adubação (Mielniczuk et al., 1969a, b; UFRGS..., 1973; UFRGS..., 1976; Manual..., 1981; Siqueira et al., 1987; CFSRS/SC, 1989, 1995). Atualmente, a CQFSRS/SC (2004) agrupou os solos desses Estados em quatro principais classes texturais. De forma semelhante, $o$ teor de argila é considerado nas recomendações dos Estados de Paraná, Mato Grosso e Minas Gerais (Boletim..., 2005; Embrapa, 2005; CFSEMG, 1999). No entanto, no Paraguai o teor de argila não estava sendo considerado na recomendação de adubação fosfatada (Fatecha, 1999). Neste trabalho, devido às limitações referentes ao número de solos pesquisados, apenas duas classes texturais foram investigadas. Assim, em futuros trabalhos realizados no Paraguai recomenda-se incluir solos com classes texturais diferentes das utilizadas nesta pesquisa.

Conforme esperado, encontrou-se diferente teor crítico de $\mathrm{P}$ conforme a classe textural do solo. Desse modo, para a classe de 210 a $400 \mathrm{~g} \mathrm{~kg}^{-1}$ de argila 
estimou-se um teor crítico de $\mathrm{P}$ de $15 \mathrm{mg} \mathrm{dm}^{-3}$, avaliado pelo método Mehlich-1, e para a classe de 410 a $600 \mathrm{~g} \mathrm{~kg}^{-1}$ encontrou-se um teor crítico de $12 \mathrm{mg} \mathrm{dm}^{-3}$ (Figura 2).

Segundo a CQFSRS/SC (2004), o teor crítico de P no solo para a primeira classe de argila é de $12 \mathrm{mg} \mathrm{dm}^{-3}$ e, para a segunda, de $9 \mathrm{mg} \mathrm{dm}^{-3}$. Portanto, os valores de teores críticos de $\mathrm{P}$ encontrados nesta pesquisa sob SPD, nas classes texturais investigadas, foram superiores aos propostos pela CQFSRS/SC (2004). De forma semelhante, em Mato Grosso, em pesquisa realizada recentemente pela Fundação MT (Boletim..., 2005), foram determinados, para essas mesmas classes de argila, teores críticos de 18 e $12 \mathrm{mg} \mathrm{dm}^{-3}$, respectivamente. Esses resultados confirmam o teor crítico de $\mathrm{P}$ encontrado no presente trabalho para a classe textural mais argilosa. No entanto, para a primeira classe o teor crítico encontrado pela Fundação MT foi $20 \%$ superior ao deste trabalho e $50 \%$ superior ao proposto pela CQFSRS/SC (2004). Schlindwein (2003), investigando experimentos sob SPD no RS, encontrou, para a classe de 410 a $550 \mathrm{~g} \mathrm{~kg}^{-1}$ de argila, teor crítico de $21 \mathrm{mg} \mathrm{dm}^{-3}$, portanto, ainda superior aos anteriores.

Os maiores teores críticos de $\mathrm{P}$ encontrados neste trabalho, e em outros realizados recentemente, podem ser explicados, em parte, pelo melhoramento genético, que proporcionou maior potencial de rendimento das culturas avaliadas, as quais, por essa razão, demandam maior quantidade de nutrientes (Schlindwein, 2003). Acresce-se a esse fato a mudança no sistema de preparo, que passou do convencional para o plantio direto, e a profundidade de amostragem, que passou a ser feita na camada mais superficial,

(a)

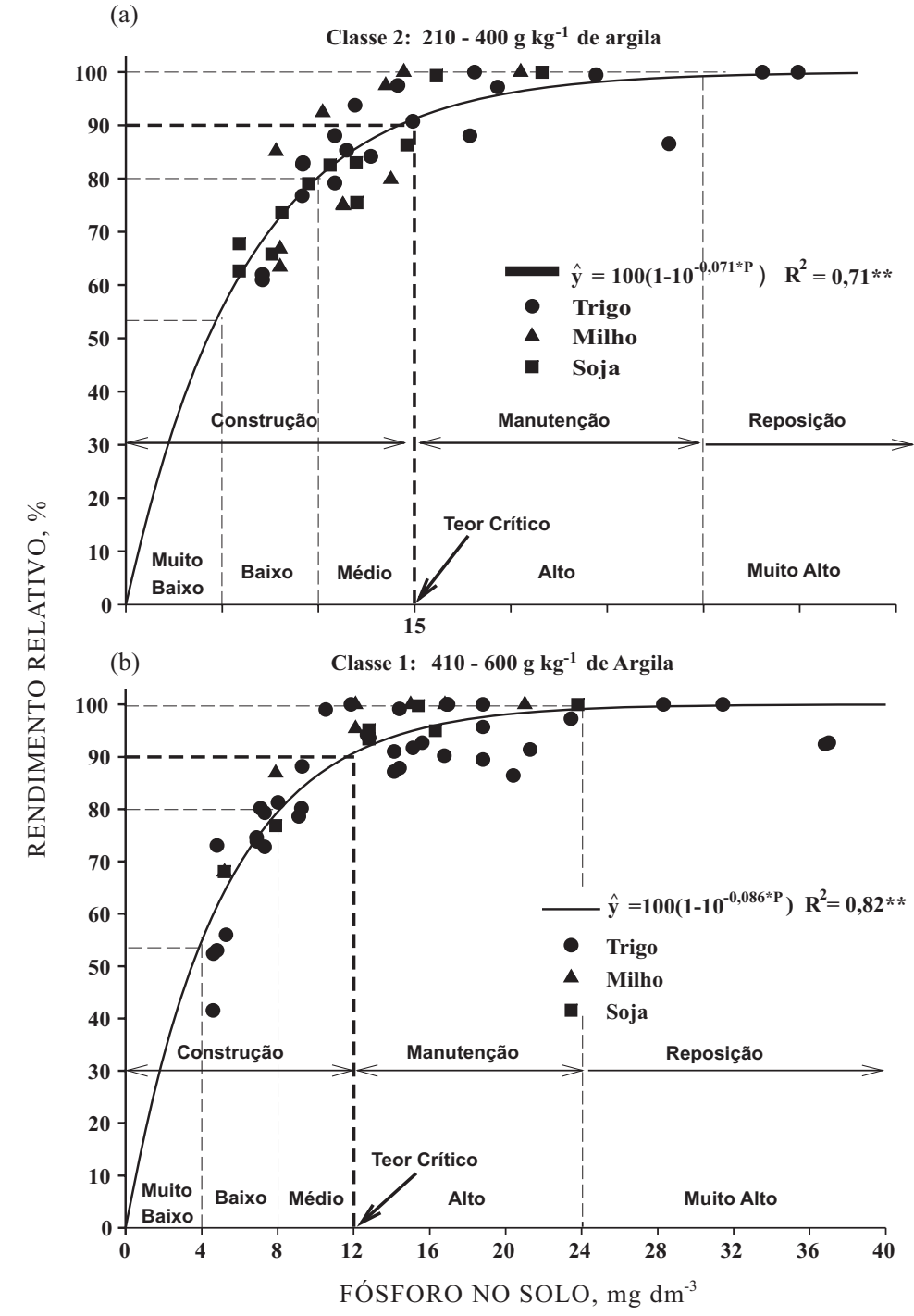

Figura 2. Teor crítico de fósforo disponível no solo na profundidade de 0-0,10 m, determinado por Mehlich1, na média de rendimentos de trigo, milho e soja sob sistema plantio direto (a) classe textural 2 (experimentos Misiones 1, Misiones 2 e Alto Paraná 1) e (b) classe textural 1 (experimentos Itapúa 1, Alto Paraná 2 e Pedro Juan Caballero 1). ** Significativo $(\mathbf{p}<0,01)$. 
onde se verifica maior concentração do nutriente. Esses fatores associados demandam que, de tempos em tempos, os teores críticos dos nutrientes sejam reavaliados, objetivando ajuste da fertilização ao sistema produtivo adotado.

Schlindwein \& Anghinoni (2000) encontraram, em experimentos de longa duração sob SPD, concentração de $\mathrm{P}$, aproximadamente, $50 \%$ maior na camada de $0-0,10 \mathrm{~m}$ do que na de $0-0,20 \mathrm{~m}$ de profundidade. Esse fato justificaria a necessidade de elevação do teor crítico do nutriente, quando da amostragem superficial sob SPD em relação à amostragem na camada de 0-0,20 m. Por sua vez, Schlindwein (2003) encontrou teores críticos de $\mathrm{P}$, analisados pelo método Mehlich-1, mesmo para a camada de 0-0,20 $\mathrm{m}$ de profundidade, maiores em solos sob SPD do que sob preparo convencional. Esse resultado sugere que, além do efeito de concentração do $\mathrm{P}$, nesse sistema conservacionista, outros processos, como o incremento no potencial de rendimento das culturas, contribuem para elevação do teor crítico do nutriente.

A recomendação de $\mathrm{P}$ atualmente utilizada no Paraguai foi feita com base em experimentos realizados na Região Oriental, em solos sob sistema convencional de cultivo, e não faz distinção de classe textural, estabelecendo o teor crítico médio de $12 \mathrm{mg} \mathrm{dm}^{-3}$, avaliado pelo método Bray (Fatecha, 1999). Esse valor correspondeu ao teor crítico proposto para solos com textura de 410 a $600 \mathrm{~g} \mathrm{~kg}^{-1}$ de argila, que coincide com a maioria dos solos da Região Oriental, porém analisado pelo método Mehlich-1. Para a classe textural menos argilosa, o teor crítico encontrado no presente trabalho foi superior ao anteriormente proposto por Fatecha (1999).

Uma vez definido o teor crítico de $\mathrm{P}$, para o método de análise escolhido e a profundidade de amostragem, faz-se necessário detalhar cada porção da curva de resposta, estabelecendo-se as faixas de interpretação agronômica (CQFSRS/SC, 2004). Essas faixas foram subdivididas eqüidistantemente com base nos teores do nutriente no solo, com maior detalhamento nas faixas de maior probabilidade de resposta à aplicação de fertilizante (CQFSRS/SC, 2004). Assim, os teores críticos de $\mathrm{P}$ no solo, ajustados pela equação de Mitscherlich, representaram o limite superior da faixa média, sendo esses valores utilizados como referência para obter as demais faixas (Figura 2).

\section{Construção da disponibilidade de fósforo no solo sob sistema plantio direto}

Neste trabalho, o incremento dos teores de $\mathrm{P}$ disponível sob SPD foi influenciado pelo histórico de adubação fosfatada e de manejo das áreas (Quadro 3). Assim, os experimentos M2, I2 e PJC1 provieram de áreas com manejo inadequado do solo, caracterizado por presença de erosão ou histórico de adubação fosfatada limitada, ou seja, ao longo dos anos foram aplicadas doses inferiores à exportação do nutriente nos grãos ou mesmo não foram fertilizadas, resultando em reduzido teor de $\mathrm{P}$ disponível. Em contraste, as áreas dos experimentos M1, I1, AP1 e AP2 (Quadro 1) vinham sendo manejadas sob SPD, em geral, há mais

Quadro 3. Quantidade necessária de $\mathrm{P}_{2} \mathrm{O}_{5}$ em $\mathrm{kg} \mathrm{ha}^{-1}$ para elevar em $1 \mathrm{mg} \mathrm{dm}^{-3}$ o teor de $\mathbf{P}$ disponível em solos com diferentes históricos de adubação fosfatada sob sistema plantio direto. Paraguai, 2005

\begin{tabular}{|c|c|c|c|c|}
\hline Experimento & Teor de argila & $\mathbf{R}^{2}$ & Equação & $\begin{array}{c}\mathrm{P}_{2} \mathrm{O}_{5} \text { para elevar } \\
\text { em } 1 \mathrm{mg} \mathrm{dm^{-3 }} \text { o } \\
\text { teor de } \\
\text { P disponivel }\end{array}$ \\
\hline \multicolumn{4}{|c|}{$\mathrm{g} \mathrm{kg}^{-1}$} & $\mathrm{~kg} \mathrm{ha}{ }^{-1}$ \\
\hline \multicolumn{5}{|c|}{ Solos com histórico de adubação adequada } \\
\hline $\mathrm{M} 1^{1 /}$ & 250 & 0,99 & $\hat{\mathrm{y}}=12,0+0,046 \mathrm{P}$ & 21,6 \\
\hline I 1 & 470 & 0,99 & $\hat{\mathrm{y}}=12,4+0,048 \mathrm{P}$ & 20,6 \\
\hline $\mathrm{AP} 1$ & 395 & 0,99 & $\hat{\mathrm{y}}=5,99+0,067 \mathrm{P}$ & 15,0 \\
\hline AP 2 & 470 & 0,99 & $\hat{\mathrm{y}}=6,32+0,058 \mathrm{P}$ & 17,2 \\
\hline Média & 396 & 0,99 & $\hat{\mathrm{y}}=9,18+0,055 \mathrm{P}$ & 18,6 \\
\hline \multicolumn{5}{|c|}{ Solos com histórico de adubação limitada } \\
\hline M 2 & 250 & 0,99 & $\hat{\mathrm{y}}=7,30+0,021 \mathrm{P}$ & 46,9 \\
\hline I 2 & 355 & 0,99 & $\hat{\mathrm{y}}=3,68+0,031 \mathrm{P}$ & 31,9 \\
\hline PJC 1 & 560 & 0,98 & $\hat{\mathrm{y}}=4,94+0,037 \mathrm{P}$ & 27,0 \\
\hline Média & 380 & 0,99 & $\hat{\mathrm{y}}=5,20+0,030 \mathrm{P}$ & 35,3 \\
\hline Média geral & & & & 25,7 \\
\hline
\end{tabular}

\footnotetext{
(1) M1: Misiones 1; M2: Misiones 2; I1: Itapúa 1; I2: Itapúa 2; AP1: Alto Paraná 1; AP2: Alto Paraná 2; PJC1: Pedro Juan Caballero.
} 
de 10 anos, e com histórico de adubação fosfatada adequada; portanto, com dose compatível com as exportações do nutriente via colheita.

No quadro 3 constata-se que, para os solos com histórico de adubação limitada, houve aumento médio de $3,0 \mathrm{mg} \mathrm{dm}^{-3}$ de $\mathrm{P}$ disponível, determinado por Mehlich-1, para cada $100 \mathrm{~kg} \mathrm{ha}^{-1}$ de $\mathrm{P}_{2} \mathrm{O}_{5}$ aplicados. Já para os solos com histórico de adubação adequada o aumento médio foi de $5,5 \mathrm{mg} \mathrm{dm}^{-3} \mathrm{de} \mathrm{P}$ disponível, para a mesma quantidade de fertilizante aplicada. Portanto, este segundo incremento foi $46 \%$ superior ao primeiro. Dessa forma, em solos com histórico de adubação adequada e não-revolvimento, há gradual saturação dos sítios de adsorção da camada superficial, resultando em menor quantidade de fertilizante necessária para construção dos níveis de P. Esse fato pode ser atribuído a um efeito combinado do bloqueio de sítios de adsorção de $\mathrm{P}$ por moléculas orgânicas provenientes das adições continuadas de resíduos vegetais, da saturação desses sítios em razão de sucessivas aplicações superficiais de fertilizantes e, finalmente, dos incrementos das percentagens de Plábil e $\mathrm{P}$ associado à biomassa microbiana (Selles et al., 1997; Oliveira et al., 2002; Lopes et al., 2004). Com isso, há possibilidade de maior eficiência dos fertilizantes fosfatados sob SPD consolidado. Por outro lado, em solos com histórico de adubação limitada e com baixo teor inicial de $\mathrm{P}$ disponível para as plantas, o caráter-dreno predomina sobre o caráter-fonte, resultando em menor elevação dos teores no solo com a aplicação do fertilizante fosfatado (Novais \& Smyth, 1999; Oliveira et al., 2002; Lopes et al., 2004).

Os resultados apresentados no quadro 3 sugerem que na fase inicial de adoção do SPD a construção da disponibilidade de $\mathrm{P}$ exige maior quantidade de fertilizante fosfatado. Contudo, com o transcorrer dos anos de fertilização e de adoção do sistema, verifica-se gradual saturação dos sítios localizados na camada superficial, permitindo que a construção da disponibilidade ocorra de forma mais intensa e rápida. Rheinheimer \& Anghinoni (2001) sugerem que, após saturação dos sítios mais ávidos, o P residual seja redistribuído em frações com menor energia de retenção e, por isso, de maior capacidade de dessorção, aumentando a disponibilidade de $\mathrm{P}$ às plantas. Além dos aspectos inerentes à química do solo, devem ser considerados outros - relacionados à atividade biológica, ciclagem de nutrientes e redução de perdas de $\mathrm{P}$-verificados sob SPD consolidado.

Neste trabalho, o incremento dos teores de P no solo sob SPD, induzido por doses de adubação fosfatada aplicada a lanço, foi mais influenciado pelo teor inicial do nutriente e histórico de adubações do que pelo teor de argila (Quadro 3). Assim, constatou-se que foram necessários em média $18,6 \mathrm{~kg} \mathrm{ha}^{-1} \mathrm{de}_{2} \mathrm{O}_{5}$ para elevar $1 \mathrm{mg} \mathrm{dm}^{-3}$ o teor de $\mathrm{P}$ disponível nos experimentos realizados com histórico de adubação adequada (M1, I1, AP1 e AP2). Por outro lado, observou-se que foram necessários, em média, $35,3 \mathrm{~kg} \mathrm{ha}^{-1}$ de $\mathrm{P}_{2} \mathrm{O}_{5}$ para elevar o teor de $\mathrm{P}$ em $1 \mathrm{mg} \mathrm{dm} \mathrm{dm}^{-3}$ nos experimentos realizados com histórico de adubação limitada (M2, I2 e PJC1). Dessa forma, a quantidade de fertilizante necessária para elevar o teor de $\mathrm{P}$ disponível foi quase duas vezes superior naqueles com histórico de adubação limitada do que naqueles com histórico de adubação adequada.

Quando os solos com histórico de adubação adequada foram separados em duas classes texturais - de 250 a $400 \mathrm{~g} \mathrm{~kg}^{-1}$ de argila (M1 e AP1) e 410 a $600 \mathrm{~g} \mathrm{~kg}^{-1}$ de argila (I1 e AP2) -, observou-se que a primeira classe de solos demandou adição de $18,3 \mathrm{~kg} \mathrm{ha}^{-1}$ de $\mathrm{P}_{2} \mathrm{O}_{5}$ para elevar $1 \mathrm{mg} \mathrm{dm}^{-3}$ de $\mathrm{P}$ disponível, e a segunda, $18,9 \mathrm{~kg} \mathrm{ha}^{-1} \mathrm{de}_{2} \mathrm{O}_{5}$. Portanto, não houve diferença em função da classe textural, contrariando o verificado anteriormente sob sistema de preparo convencional. Os resultados observados neste trabalho, provavelmente, estão associados a efeitos combinados de mínima mobilização do solo, à elevada concentração de P na camada superficial, resultante da aplicação superficial de adubo fosfatado e de calcário e da pequena redistribuição vertical do nutriente no solo, e, ainda, ao maior teor de matéria orgânica na camada superficial. Dessa forma, ficou evidenciado não haver influência do teor de argila (na faixa entre 250 e $600 \mathrm{~g} \mathrm{~kg}^{-1}$ ) na elevação do teor de P no solo em áreas sob SPD consolidado e com histórico de adubação adequada; por outro lado, ressaltou-se a importância do teor inicial de $\mathrm{P}$ do solo. No entanto, destaca-se que o número de solos investigados neste estudo foi reduzido, devendo esse resultado ser confirmado por um conjunto maior de solos.

\section{Recomendação preliminar de adubação de fósforo sob sistema plantio direto no Paraguai}

O conceito de adubação proposto para o Paraguai foi adaptado do atualmente utilizado no RS e SC (Gianello \& Wiethölter, 2004). O sistema sugerido é composto por uma adubação corretiva, para as faixas abaixo do teor crítico, e de manutenção/reposição, para as faixas acima deste teor. Considerando as condições econômicas da maioria dos produtores do Paraguai, optou-se por uma adubação corretiva gradual associada à adubação de manutenção. Assim, as doses de correção do teor de $\mathrm{P}$ no solo foram calculadas para atingir o teor crítico em três cultivos. Com base nos resultados apresentados no quadro 3 , foi estimado que, em média, havia necessidade de adicionar $25,7 \mathrm{~kg}$ de $\mathrm{P}_{2} \mathrm{O}_{5}$ para elevar $1 \mathrm{mg} \mathrm{dm}^{-3}$ de $\mathrm{P}$ disponível no solo. Assim, a dose de correção de $\mathrm{P}_{2} \mathrm{O}_{5}$ para as faixas muito baixa e baixa foi obtida multiplicando-se esse valor pela diferença entre o valor do teor crítico e o valor superior da faixa em questão (CQFSRS/SC, 2004). O valor obtido foi parcelado em 50, 30 e $20 \%$, a serem aplicados no primeiro, segundo e terceiro cultivos, respectivamente (Quadro 4). Para a faixa média, optou-se por recomendar o valor de $25 \mathrm{~kg} \mathrm{ha}^{-1} \mathrm{de}_{2} \mathrm{O}_{5}$ na adubação de correção apenas no primeiro cultivo. O objetivo principal da adubação de correção é elevar 
Quadro 4. Recomendação preliminar de adubação fosfatada corretiva de $P_{2} O_{5}$ para trigo, milho e soja sob sistema plantio direto. Paraguai, 2005

\begin{tabular}{llcc}
\hline \multirow{2}{*}{ Classe } & \multicolumn{3}{c}{ Recomendação para três cultivos } \\
\cline { 2 - 4 } & Primeiro cultivo & Segundo cultivo & Terceiro cultivo \\
\cline { 3 - 4 } & $80+\mathrm{M}$ & $\mathrm{kg} \mathrm{ha}^{-1} \mathrm{de}_{2} \mathrm{O}_{5}+\mathrm{M}$ \\
Muito baixo & $35+\mathrm{M}$ & $70+\mathrm{M}$ & $30+\mathrm{M}$ \\
Baixo & $25+\mathrm{M}$ & $35+\mathrm{M}$ & $\mathrm{M}$ \\
Médio & $\mathrm{M}^{2 /}$ & $\mathrm{M}$ & $\mathrm{M}$ \\
Alto & $\mathrm{R}^{1 /}$ & $\mathrm{M}$ & $\mathrm{R}$ \\
Muito alto & $\mathrm{R}$ & $\mathrm{R}$
\end{tabular}

${ }^{(1)} \mathrm{R}$ : reposição (exportação das culturas). $\mathrm{O}$ valor $\mathrm{R}$ para as seguintes culturas é: trigo: $10 \mathrm{~kg}$ de $\mathrm{P}_{2} \mathrm{O}_{5}$, milho: 8 kg de $\mathrm{P}_{2} \mathrm{O}_{5}$ e soja: $12 \mathrm{~kg}$ de $\mathrm{P}_{2} \mathrm{O}_{5}$ por $\mathrm{t}$ de grãos produzidos. ${ }^{(2)} \mathrm{M}$ : manutenção ( $\left.\mathrm{R} \times 1,25\right)$. $\mathrm{O}$ fator 1,25 corresponde a possíveis perdas de nutrientes do sistema de manejo.

os teores no solo a níveis próximos ao máximo retorno econômico (CQFSRS/SC, 2004). Essa recomendação é apresentada de forma preliminar, devendo passar por uma validação de campo, por meio do acompanhamento de lavouras comerciais.

A adubação de manutenção foi estimada com base na exportação de grãos, acrescida de $25 \%$, para compensar possíveis perdas do sistema. As culturas de milho e trigo exportam em média 8 e $10 \mathrm{~kg}$ de $\mathrm{P}_{2} \mathrm{O}_{5}$ por $\mathrm{t}$ de grãos produzidos, respectivamente. A soja apresenta exportação do nutriente superior à dessas culturas, alcançando $14 \mathrm{~kg}$ de $\mathrm{P}_{2} \mathrm{O}_{5}$ por t de grãos (CQFSRS/SC, 2004). No entanto, segundo o Boletim de Pesquisa de Soja (2005), o valor médio de exportação da oleaginosa seria de $10 \mathrm{~kg}$ de $\mathrm{P}_{2} \mathrm{O}_{5}$ ha ${ }^{-1}$ por t de grãos. Neste trabalho, optou-se por utilizar uma média desses valores, estabelecendo-se $12 \mathrm{~kg}$ de $\mathrm{P}_{2} \mathrm{O}_{5}$ por $\mathrm{t}$ de grãos de soja produzidos. Assim, a dose para manutenção proposta foi de $10,12,5$ e $15 \mathrm{~kg} \mathrm{ha}^{-1} \mathrm{de}$ $\mathrm{P}_{2} \mathrm{O}_{5}$, por $\mathrm{t}$ de grãos produzidos de milho, trigo e soja, respectivamente.

Por outro lado, quando o teor do nutriente no solo se encontrar na faixa alta, o objetivo da recomendação será de manter o teor nesta faixa. Quando o teor do nutriente no solo estiver na faixa muito alta, as adubações poderão ser somente de reposição, ou até mesmo poderão ser temporariamente dispensadas, devido à relação de preços entre o insumo e o produto (Gianello \& Wiethölter, 2004).

\section{CONCLUSÕES}

1. O teor crítico de $\mathrm{P}$, determinado sob sistema plantio direto para trigo, soja e milho, estimado para solos com 410 a $600 \mathrm{~g} \mathrm{~kg}^{-1}$ de argila (classe 1), é de $12 \mathrm{mg} \mathrm{dm}^{-3}$, e para solos com 210 a $400 \mathrm{~g} \mathrm{~kg}^{-1}$ de argila (classe 2), de $15 \mathrm{mg} \mathrm{dm}^{-3}$.
2. Em solos com baixo teor de P e com histórico de adubação limitada é necessário aplicar em média $35,3 \mathrm{~kg} \mathrm{ha}^{-1}$ de $\mathrm{P}_{2} \mathrm{O}_{5}$ para elevar $1 \mathrm{mg} \mathrm{dm}^{-3}$ de $\mathrm{P}$ disponível no solo; para solos com teor médio a alto e com histórico de adubação adequada, é necessário aplicar $18,6 \mathrm{~kg} \mathrm{ha}{ }^{-1}$ de $\mathrm{P}_{2} \mathrm{O}_{5}$. Essas quantidades não mostraram relação com a granulometria do solo, sendo utilizado o valor médio de $25 \mathrm{~kg} \mathrm{ha}^{-1}$ de $\mathrm{P}_{2} \mathrm{O}_{5}$ para elevação de $1 \mathrm{mg} \mathrm{dm}^{-3}$ de $\mathrm{P}$ disponível no solo para estabelecimento da adubação corretiva.

\section{AGRADECIMENTOS}

À CAPECO (Câmara Paraguaia de Exportadores de Cereais e Oleaginosas), pelo financiamento desta pesquisa; ao Eng.-Agr. Luis Enrique Cubilla Ramos e ao Eng. César Jure Yunis, pelo apoio a este projeto; à Universidade Nacional de Assunção (UNA-FCA-PJC); aos institutos de pesquisa: Centro Tecnológico Agropecuário do Paraguai (CETAPAR-JICA), Centro Regional de Investigação Agrícola do Ministério de Agricultura (CRIA-MAG) e Cooperativa Agrícola de Naranjal (COPRONAR); aos produtores rurais Rudi Dressler e Eugênio Mañko; à LACTOSUR; à Rede Paraguaia de Laboratórios (RENALAS - Red Nacional de Laboratórios de Analisis de Suelos); e ao técnico de laboratório Luiz Finamor.

\section{LITERATURA CITADA}

AMADO, T.J.C.; MIELNICZUK, J. \& AITA, C. Recomendação de adubação nitrogenada para o milho no RS e SC adaptada ao uso de culturas de cobertura do solo, sob sistema plantio direto. R. Bras. Ci. Solo, 26:241-248, 2002. 
BAYER, C.; MIELNICZUK, J.; AMADO, T.J.C.; MARTINNETO, L. \& FERNANDES, S.V. Organic matter storage in a sandy clay loam Acrisol affected by tillage and cropping systems in Southern Brazil. Soil Till. Res., 54:101-109, 2000 .

BOLETIM DE PESQUISA DE SOJA. Fundação Mato Grosso. 9.ed. Central de Texto Rondonópolis, 2005. 230p.

COMISSÃO DE FERTILIDADE DO SOLO - CFSRS/SC. Recomendações de adubação e calagem para os Estados do Rio Grande do Sul e Santa Catarina. 2.ed. Passo Fundo, Sociedade Brasileira de Ciência do Solo - Núcleo Regional Sul, Embrapa/CNPT, 1989. 128p.

COMISSÃO DE FERTILIDADE DO SOLO - CFSRS/SC. Recomendações de adubação e calagem para os Estados do Rio Grande do Sul e Santa Catarina. 3.ed. Passo Fundo, Sociedade Brasileira de Ciência do Solo - Núcleo Regional Sul, Embrapa/CNPT, 1995. 224p.

COMISSÃO DE FERTILIDADE DO SOLO DO ESTADO DE MINAS GERAIS -CFSEMG. Recomendações para uso de corretivos e fertilizantes em Minas Gerais: $5^{\text {a }}$ aproximação. Viçosa, MG, 1999. 360p.

COMISSÃO DE QUÍMICA E FERTILIDADE DO SOLO CQFSRS/SC. Manual de recomendações de adubação e calagem para os estados do Rio Grande do Sul e Santa Catarina. 10.ed. Porto Alegre, Sociedade Brasileira de Ciência do Solo - Núcleo Regional Sul, 2004. 394p.

CUBILLA, A.M.M. Calibração visando recomendações de fertilização fosfatada para as principais culturas de grãos sob sistema plantio direto no Paraguai. Santa Maria, Universidade Federal de Santa Maria, 2005.160p. (Tese de Mestrado)

DERPSCH, R. \& BENITES, J. Agricultura conservacionista no mundo. In: REUNIÃO BRASILEIRA DE MANEJO E CONSERVAÇÃO DO SOLO E DA ÁGUA, 15., Santa Maria, 2004. Anais. Santa Maria, Sociedade Brasileira de Ciência do Solo, 2004. CD ROM.

ELTZ, F.L.F.; PEIXOTO, R.T.G. \& JASTER, F. Efeitos de sistemas de preparo do solo nas propriedades físicas e químicas de um latossolo bruno álico. R. Bras. Ci. Solo, 13:259-267, 1989.

EMPRESA BRASILEIRA DE PESQUISA AGROPECUÁRIA EMBRAPA. Tecnologias de produção de soja - região central do Brasil. Londrina, Embrapa Soja, 2005. 239p. (Sistema de Produção/Embrapa Soja, 6)

FAOSTAT data. Disponível em: <http://www.faostat.fao.org $>$. Acessado em 15 fev. 2005.

FATECHA, A. Guía para la fertilización de cultivos anuales e perennes de la región oriental del Paraguay. Caacupé, Ministerio de Agricultura y Ganadería, 1999. 23p.

GIANELlO, C. \& WIETHÖLTER, S. Novo sistema de adubação para as culturas de grãos nos Estados do Rio Grande do Sul e de Santa Catarina. In: REUNIÃO SULBRASILEIRA DE CIÊNCIA DO SOLO, 5., Florianópolis, 2004 Anais. Florianópolis, Sociedade Brasileira de Ciência do Solo, 2004. CD ROM.
LOPES, A.S.; WIETHÖLTER, S.; GUILHERME, L.R.G. \& SILVA, C.A. Sistema plantio direto: Bases para o manejo da fertilidade do solo. São Paulo, Associação Nacional para Difusão de Adubos, 2004. 115p.

LÓPEZ, O.E.; GONZALEZ, E.; DE LLAMAS, P.A.; MOLINAS, A.S.; FRANCO, E.S.; GARCIA, S. \& RIOS, E. Reconocimiento de suelos y capacidad de uso de las tierras; Región Oriental. Asunción, MAG /Dirección de Ordenamiento Ambiental/Banco Mundial, 1995. 28p.

MANUAL de adubação e calagem para cultivos agrícolas do Rio Grande do Sul e Santa Catarina. Trigo Soja, 56:1-34, 1981.

MARTINS, J.R. \& GONÇALVES, C.N. Estudo da adsorção em diferentes profundidades de um solo sob cultivo convencional e plantio direto. In CONGRESSO BRASILEIRO DE CIÊNCIA DO SOLO, 26., Rio de Janeiro, 1997. Anais. Rio de Janeiro, Sociedade Brasileira de Ciência do Solo, 1997. CD ROM.

MIELNICZUK, J.; LUDWICK, A. \& BOHNEN, H. Recomendações de adubo e calcário para as principais culturas do Estado do Rio Grande do Sul. Porto Alegre, Universidade Federal do Rio Grande do Sul, 1969a. 36p. (BoletimTécnico, 2)

MIELNICZUK, J.; LUDWICK, A.; VOLKWEISS, S.; PATELLA, J.F. \& MACHADO, M.O. Estudos iniciais de calibração de análises para fósforo e potássio do solo com a cultura do trigo. Porto Alegre, Universidade Federal do Rio Grande do Sul, 1969b. 10p.

MUZILLI, O. Influência do sistema de plantio direto, comparado ao convencional, sobre a fertilidade da camada arável do solo. R. Bras. Ci. Solo, 7:95-102, 1983.

NOVAIS, R.F. \& SMYTH, T.J. Fósforo em solo e planta em condições tropicais. Viçosa, MG, Universidade Federal de Viçosa, 1999. 399p.

OLIVEIRA, F.H.T.; NOVAIS, R.F.; ALVAREZ V., V.H.; CANTARUTTI, R.B. \& BARROS, N.F. Fertilidade do solo no sistema plantio direto. In: ALVAREZ V., V.H.; SCHAEFER, C.E.G.R.; BARROS, N.F.; MELLO, J.W.V. \& COSTA, L.M., eds. Tópicos em ciência do solo. Viçosa, MG, Sociedade Brasileira de Ciência do Solo, 2002. v.2. p.393-486.

RED NACIONAL DE LABORATORIOS DE ANÁLISIS DE SUELO - RENALAS. Primer taller de control de calidad de los laboratorios de suelos e recomendación de fertilización nitrogenada, fosfatada e potássica para trigo, maiz e soja en siembra directa en Paraguay. Assunción, 2005. CD ROM.

RHEINHEIMER, D.S. \& ANGHINONI, I. Distribuição do fósforo inorgânico em sistemas de manejo de solo. Pesq. Agropec. Bras., 36:151-160, 2001.

SÁ, J.C.M. Manejo da fertilidade do solo no plantio direto. Castro, Fundação ABC, 1993. 96p.

SCHLINDWEIN, J.A. Calibração de métodos de determinação e estimativa de doses de fósforo e potássio em solos sob sistema plantio direto. Porto Alegre, Universidade Federal do Rio Grande do Sul., 2003. 169p. (Tese de Doutorado)

SCHLINDWEIN, J.A. \& ANGHINONI, I. Variabilidade vertical de fósforo e potássio disponíveis e profundidade de amostragem do solo no sistema plantio direto. Ci. Rural, 30:611-617, 2000 . 
SELLES, F.; KOCHHANN, R.A.; DENARDIN, J.E.; ZENTNER, R.P. \& FAGANELLO, A. Distribution of phosphorus fractions in a Brazilian Oxisol under different tillage systems. Soil Till. Res., 44:23-34, 1997.

SIDIRAS, N. \& PAVAN, M.A. Influência do sistema de manejo do solo no seu nível de fertilidade. R. Bras. Ci. Solo, 9:249254,1986

SIQUEIRA, O.J.F.; SCHERER, E.E.; TASSINARI,G.; ANGHINONI, I.; PATELLA, J.F.; TEDESCO, M.J.; MILAN, P.A. \& ERNANI, P.R. Recomendações de adubação e calagem para os Estados do Rio Grande do Sul e Santa Catarina. Passo Fundo, Embrapa/CNPT, 1987. 100p.
TEDESCO, M.J.; GIANELLO, C.; BISSANI, C.A.; BOHNEN, H. \& VOLKWEISS, S.J. Análises de solo, plantas e outros materiais. 2.ed. Porto Alegre, Universidade Federal do Rio Grande do Sul, 1995. 174p. (Boletim Técnico, 5)

UNIVERSIDADE FEDERAL DO RIO GRANDE DO SUL UFRGS. Tabelas de adubação corretiva e adubação de manutenção para os solos e culturas dos Estados do Rio Grande do Sul e Santa Catarina. Porto Alegre, 1973. 11p.

UNIVERSIDADE FEDERAL DO RIO GRANDE DO SUL UFRGS. Tabelas de adubação corretiva e adubação de manutenção para os solos e culturas dos Estados do Rio Grande do Sul e Santa Catarina. Porto Alegre, 1976. 15p. 